\title{
Modeling of Octagonal Transformer for Wireless Telecommunication Applications
}

\author{
Mokhtaria Derkaoui
}

\begin{abstract}
The work presented in this paper concerns the modeling of an integrated transformer in monolithic technology for high frequencies containingcoils of planar type and magnetic circuit made of several layers of materials. Circular, square and polygonal shapes of the planar coils are the important difference regarding transformer topologies. In this work, we have chosen the stacked octagonal form of coils. We have opted for the Wheeler method and the S-parameters for determining the geometrical and the electrical parameters. The electrical $\pi$ model presented summarizes perfectly the various parasitic effects generated by stacked layers of different materials constituting the transformer.The electromagnetic simulation, by using COMSOL Multiphysics 4.3 software, illustrates the current density and the distribution of magnetic field lines.
\end{abstract}

Index Terms - Planar, transformer, octagonal, integration, RF.

\section{INTRODUCTION}

Power electronics has never stopped to advance, since its appearance. Now, this discipline exists in the majority of electrical systems, ensuring control of energy supply and the integrity of the components. Passive components occupy $80 \%$ of electrical circuits' surface as the low power converter. At present, the integration of active components has now become a classical thing, however, only the integration of passive components remains the obstacle of miniaturization [1], [2]. At the heart of isolated converters, there is an essential element, the transformer. To overcome the problem of integration and reducing the size of the transformer, the planar components were introduced [3]-[5]. The transformer is an inductive component formed by a thin magnetic circuit, usually made of ferrite, on which conductive coils are deposited. In these years, planar transformers are widely used in monolithic integrated circuits and are implemented in many systems for several applications [6], [7].

\section{PRESENTATION OF THE MiCROTRANSFORMER}

A transformer is an inductive component, it is considered as a device whose operation is based on mutual coupling between at least two inductors. Fig. 1 shows a schematic diagram of an ideal transformer of two coils.

In low frequencies, the behavior of the inductor is modeled by a pure inductance $L$ in series with a resistance

Manuscript received May 18, 2020; revised August 2, 2020

Mokhtaria Derkaoui is with LARATIC laboratory, National Institute of Telecommunications \& ICT (INTTIC-Oran), Algeria (e-mail: mderkaoui@inttic.dz).
Rs, which characterizes the different losses (Fig. 2a). Whereas, in high frequencies, the inductance $L$ in series with resistance $R s$ are in parallel with capacitance $C s$ which characterizes the capacitive coupling between turns (Fig. 2b).

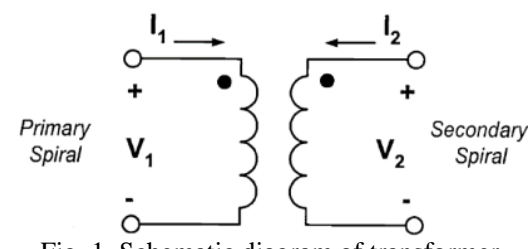

Fig. 1. Schematic diagram of transformer

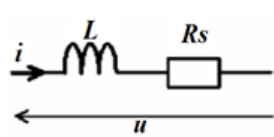

(a)

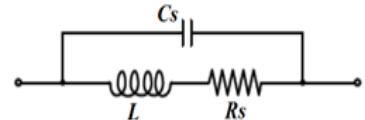

(b)
Fig. 2. Simplified model of inductor: (a) Low frequency, (b) High frequency.

The behavior of an integrated planar inductor on silicon was proposed in simple " $\pi$ " model by Nguyen and Meyer and then was developed by Ashby and al (Fig. 3a). After, Yue and Yong presented a similar model with more appropriate parameters (Fig. 3b) [8], [9]. Later, Yamaguchi and al proposed the first equivalent circuit composed of magnetic material placed above or below the inductance (Fig. 3c), but the model become very complicated [10]; afterwards, this work was simplified to show the different layers superimposed one on the other (Fig. 3d) [11].

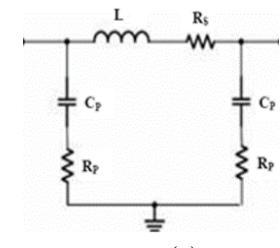

(a)

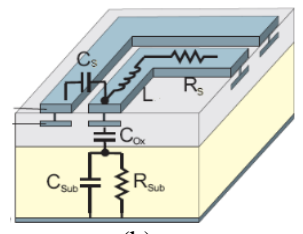

(b)

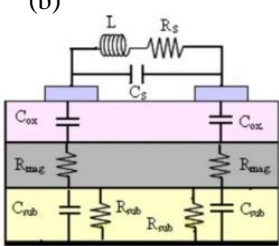

(d) (c)

Fig. 3. (a) Simple $\pi$ model, (b) Cross section of planar inductor, (c) Ferromagnetic inductor, (d) Cross section of planar inductor on ferrite

As a transformer is a coupling between two inductors, the integrated planar transformer composed of two integrated planar inductors was proposed by [12] (Fig. 4) which the coils are spiral with square form. 


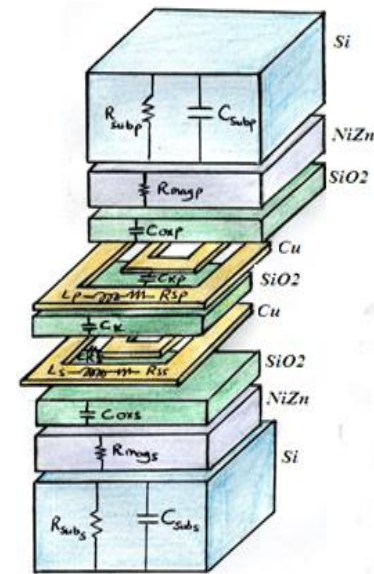

(a)

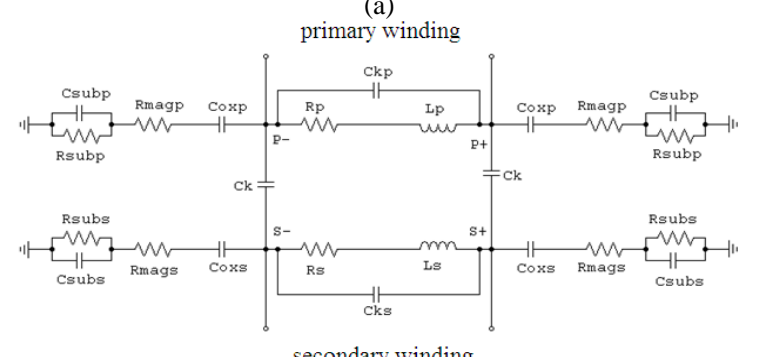

(b)

Fig. 4. (a) 3D cross section of an integrated planar transformer with square form of coils [12], (b) Equivalent electrical circuit.

\section{PRESENTATION OF OCTAgOnal Planar TRANSFORMER}

The coil's shape is an important distinction regarding inductor and transformer topologies. Circular, square and polygonal spirals have already mentioned to constitute their coils. In this study, we demonstrate another transformer model whose coils are of octagonal planar shape (Fig. 5).

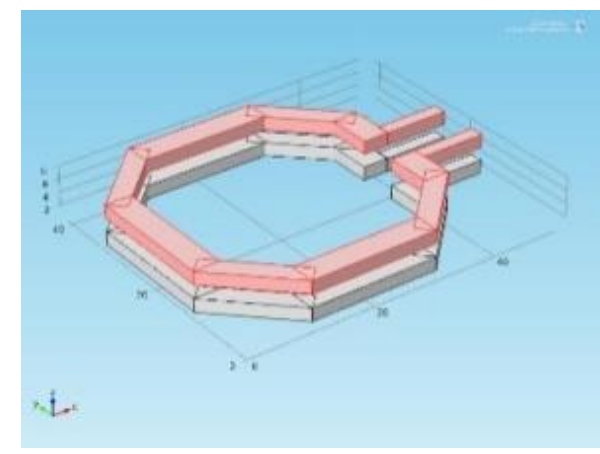

Fig. 5. Octagonal topology of coils.

\section{A. Inductance Value's Calculation}

The calculation's method developed by Wheeler [13] allows the inductance's evaluation of hexagonal, octagonal or square form of coils, realized in a discrete way. This method is easy to implement, it has a low error compared with other methods and it remains valid for reduced number of turns. The inductance $L$ given by Wheeler method is represented by Eq. (1),

$$
L=k_{1} \mu_{0} \frac{n^{2} d_{a v g}}{1+k_{2} A_{m}}
$$

$d_{\text {avg }}$ is the average diameter, $A_{m}$ is the form factor, $n$ is the number of turns and $\mu_{0}$ is the vacuum permeability.

$$
\begin{gathered}
d_{\text {avg }}=\frac{d_{\text {out }}+d_{\text {in }}}{2} \\
A_{m}=\frac{d_{\text {out }}-d_{\text {in }}}{d_{\text {out }}+d_{\text {in }}}
\end{gathered}
$$

The coefficients $k_{1}$ and $k_{2}$ depend on the different topologies of coils (Table I),

TABLE I: VALUES OF COEFFICIENTS $K_{1}$ AND $K_{2}$ USED IN WHEELER

\begin{tabular}{c|c|c}
\multicolumn{3}{c}{ METHOD } \\
Form & $\boldsymbol{k}_{\mathbf{1}}$ & $\boldsymbol{k}_{\mathbf{2}}$ \\
\hline Square & 2.34 & 2.75 \\
Hexagonal & 2.33 & 3.82 \\
octagonal & 2.25 & 3.55 \\
\hline
\end{tabular}

Conferring to the form factor $A_{m}$, we can obtain the hollow or full inductors. Thus, a hollow inductor has a higher inductance than a full one because the turns located near the center of the spiral contribute to decrease the mutual positive inductances and increase the mutual negative inductances [13].

\section{B. Feed Lines Position}

Such as the stacked topology is chosen in Fig. 5, the relative position between primary and secondary coils is considered in terms of the location of their feed lines. The proposition is to have the secondary completely rotated by 180-degree of the primary (Fig. 6). This configuration tends to weaken the coupling between coils because the feed lines are uncovered. The choice between these structures shows which one has better performance.

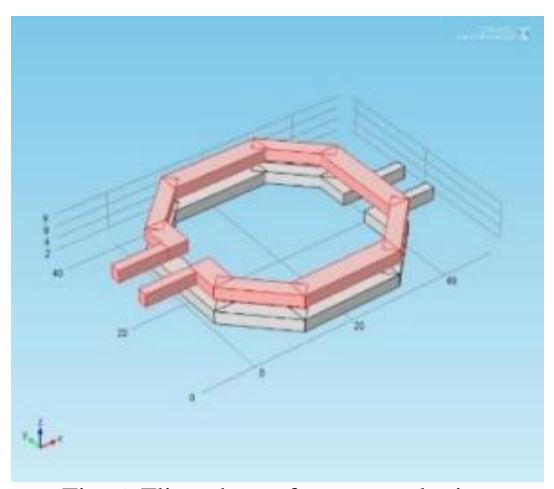

Fig. 6. Flipped transformer topologies.

The inductance measurement results for transformers with flipped and non-flipped topologies are shown in Fig. 7. When the flipped topology is adopted, the curves illustrate a significant reduction of the resonant frequency. Selfinductances remain unchanged and magnetic coupling is weaken, in low frequency. For frequencies greater than $100 \mathrm{MHz}$, flipped transformer demonstrates a lower minimum insertion loss, whereas, the non-flipped transformer presents a proper performance for a wider band.

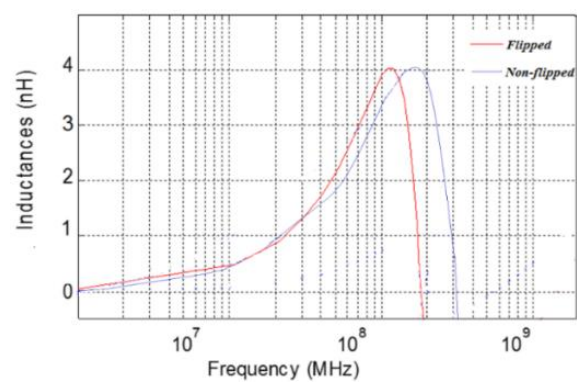

Fig. 7. Flipped and non-flipped inductances. 


\section{Geometrical Parameters' Calculation}

The octagonal planar coils are geometrically described by the outer and inner diameters, the number of turns, the width, the thickness, the spacing between turns and the total length for each coil. We have opted for an outer diameter of 3000 $\mu \mathrm{m}$ and an inner diameter of $2000 \mu \mathrm{m}$; the angles are limited to multiples of 45 degrees.

1) Thickness of coil

The calculation of thickness depends on skin thickness $\delta$ Eq. (4) which determines the zone where the current concentrates in a conductor (Fig. 8) [14].

$$
\delta=\sqrt{\frac{\rho_{C u}}{\pi \cdot \mu_{C u} \cdot f}}
$$

$\rho_{c u}$ and $\mu_{c u}$ are respectively resistivity and permeability of copper, $f$ is the operating frequency in high frequencies.

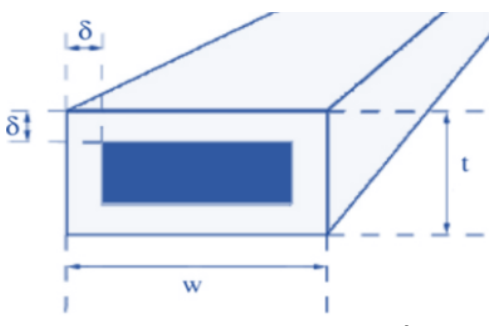

Fig. 8. Volume delimited by the skin effect $\delta$ in a conductor.

To avoid the problem of the skin effect and make the current flowing in the entire conductor, it is necessary to fulfill the following condition:

$$
t \leq 2 . \delta
$$

The current density $j(x)$ for $x$ ranging from 0 to $t / 2$ and its average value $j_{\text {avg }}$ with $J_{0}=10^{9} \mathrm{~A} / \mathrm{m}^{2}$ [15], are given by expressions 6 and 7;

$$
\begin{aligned}
& j(x)=j_{0} e^{-i\left(\frac{x}{\delta}\right)} e^{-\left(\frac{x}{\delta}\right)} \\
& j_{\text {avg }}=j_{0} \frac{\left[e^{-\left(\frac{t}{2 \delta}\right)}+1\right]}{2}
\end{aligned}
$$

The electric current $i$ (Eq. 8) which pass through the conductor is a function of the current density and the conductor's section. This last is a function of the width $w$ and the thickness $t$ of the planar coil (Eq. 9)

$$
\begin{gathered}
i=S_{c} \cdot j_{a v g} \\
S_{c}=w \cdot t
\end{gathered}
$$

2) Spacing between turns

$$
S=\frac{d_{o u t}-d_{i n}-(2 . w \cdot n)}{2 \cdot(n-1)}
$$

3) Total length

$$
l t=\left(4 n\left(d_{\text {out }}-(n-1) s-(n . w)\right)\right)-s
$$

4) Width

$$
w=\frac{\left[d_{o u t}-d_{\text {in }}-2 . s .(n-1)\right]}{2 . n}
$$

\section{Modeling Of InTEgRated Planar OCtAgOnAL TRANSFORMER}

In this work, the planar transformer is composed of two octagonal coils in copper, superimposed on a ferromagnetic layer of ferrite (NiZn), and isolated from there by a dioxide layer of silicon dioxide $\left(\mathrm{SiO}_{2}\right)$; all these layers of the different materials are superimposed on a layer of silicon (Si), which serves as a substrate. This transformer operates at a high frequency of the order of $100 \mathrm{MHz}$ (Fig. 9).

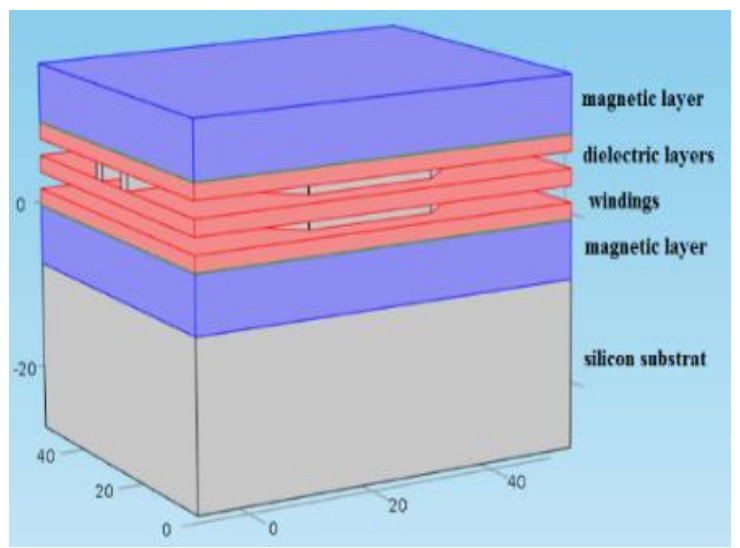

Fig. 9. 3D cross section of the integrated planar octagonal transformer.

The magnetic core volume is calculated by Eq. (13)

$$
V=\frac{W}{W_{v \max }}
$$

$W$ represents the total magnetic stored energy in the transformer's coils Eq. (14)

$$
w=\frac{1}{2} \cdot \mathrm{L} \cdot \mathrm{i}^{2}
$$

$\mathrm{W}_{\mathrm{vmax}}$ represents maximum volume density of energy (Eq. 15)

$$
W_{v \max }=\frac{B_{\max }^{2}}{2 \cdot \mu_{0} \cdot \mu_{r \mathrm{NiZn}}}
$$

$B_{\max }=0.3 \mathrm{~T}$ is the maximal saturation induction,

$\mu_{r \mathrm{NiZn}}=1400$ is the relative permeability of NiZn ferrite,

Therefore, after calculation, the NiZn magnetic core's volume equals $0.080 \mathrm{~mm}^{3}$, which is necessary to store $3.125 \mathrm{~nJ}$ of energy.

The core thickness is represented by the following expression,

$$
e_{\text {NiZn }}=\frac{V}{d_{\text {out }}^{2}}
$$

\section{A. Technological Parameters' Calculation}

The equivalent electrical circuit (Fig. 10) extracted from (Fig. 9) demonstrates the electrical behavior of the integrated octagonal planar transformer.

The equivalent circuit contains different electrical parameters, which are the inductances $L$ and serial resistance $R_{s}$ of the coils, oxide capacitance $C_{o x}$ of the dielectric layer, magnetic resistance $R_{m a g}$ of the ferrite layer, resistances $R_{\text {sub }}$ and capacitance $C_{s u b}$ associate to the silicon substrate, coupling capacitance $C_{K}$ between the two coils.

The analytical expressions of different elements constituting the electrical model (Fig. 10) of the octagonal transformer are represented by the following Equations: 
$\rho_{C u}=1.7 .10^{-8} \Omega . \mathrm{m}$

$$
R_{s}=\rho_{c u} \cdot \frac{l_{t}}{w \cdot t_{e f f}}
$$

$t_{\text {eff }}$ is given by the expression below

$$
\begin{aligned}
& \mathrm{t}_{\text {eff }}=\delta\left(1-\mathrm{e}^{-\left(\frac{\mathrm{t}}{\delta}\right)}\right) \\
& \mathrm{R}_{\text {sub }}=2 \cdot \rho_{\mathrm{Si}} \cdot \frac{\mathrm{e}_{\mathrm{Si}}}{\mathrm{w} \cdot \mathrm{l}_{\mathrm{t}}}
\end{aligned}
$$

$\rho_{\mathrm{Si}}=18.5 \Omega . \mathrm{m}$

$$
\mathrm{R}_{\mathrm{mag}}=2 \cdot \rho_{\mathrm{NiZn}} \cdot \frac{\mathrm{e}_{\mathrm{NiZn}}}{\mathrm{w} \cdot \mathrm{l}_{\mathrm{t}}}
$$

$\rho_{\mathrm{NiZn}}=10^{3} \Omega \cdot \mathrm{m}$

$$
\mathrm{C}_{\mathrm{oxp}}=\frac{1}{2} \cdot \varepsilon_{0} \varepsilon_{\text {rox }} \cdot \frac{\mathrm{w} \cdot \mathrm{l}_{\mathrm{t}}}{\mathrm{t}_{\mathrm{ox}}}
$$

$\varepsilon_{\text {rox }}=3.9$

$$
\mathrm{C}_{\mathrm{sub}}=\frac{1}{2} \cdot \varepsilon_{0} \varepsilon_{\mathrm{rSi}} \cdot \frac{\mathrm{w} \cdot \mathrm{l}_{\mathrm{t}}}{\mathrm{e}_{\mathrm{si}}}
$$

$\varepsilon_{r \mathrm{Si}}=11.8$

$$
\begin{aligned}
& \mathrm{C}_{\mathrm{kp}}=\frac{1}{2} \cdot \varepsilon_{\mathrm{ox}} \cdot \frac{\mathrm{t}_{\mathrm{t}}}{\mathrm{s}} \\
& \mathrm{C}_{\mathrm{k}}=\varepsilon_{0} \varepsilon_{\mathrm{r} \text { air }} \cdot \frac{\mathrm{d}_{\text {out }}^{2}}{\mathrm{t}_{\mathrm{ox}}}
\end{aligned}
$$

$\varepsilon_{r \text { air }}=1$

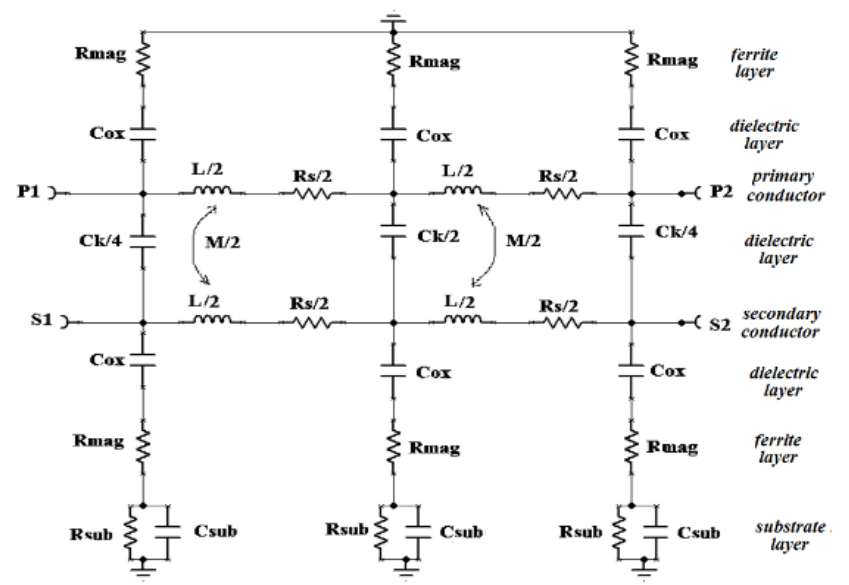

Fig. 10. Equivalent electrical circuit of the integrated planar transformer.

\section{B. Geometrical and Electrical Dimensioning Results}

The calculated geometric and electrical parameters of the octagonal planar transformer are shown in Table II.

TABLE II: RESULTS OF CALCULATED PARAMETERS

\begin{tabular}{l|l}
\hline Dimensioning parameters & values \\
\hline Outer diameter $d_{\text {out }}$ & $3000 \mu \mathrm{m} 2000$ \\
Inner diameter $d_{\text {in }}$ & $\mu \mathrm{m}$ \\
Thickness of magnetic core $e_{\mathrm{NiZn}}$ & $9 \mu \mathrm{m}$ \\
Thickness of coil $t$ & $13,13 \mu \mathrm{m}$ \\
Conductor's skin thickness $\delta$ & $6,56 \mu \mathrm{m}$ \\
Width of coil $w$ & $500 \mu \mathrm{m}$ \\
Total length of coil $L t$ & $10 \mathrm{~mm}$ \\
Primary inductance & $4,13 \mathrm{nH}$ \\
Secondary inductance & $2,9 \mathrm{nH}$ \\
Serial resistance $R s$ & $0.06 \Omega$ \\
Magnetic resistance $R_{\text {mag }}$ & $3.6 \mathrm{~K} \Omega$ \\
Substrate resistance $R_{\text {sub }}$ & $2.42 \mathrm{~K} \Omega$ \\
Substrate capacitance $C_{s u b}$ & $2.5 \mathrm{pF}$ \\
Oxide capacitance $C_{o x}$ & $3.66 \mathrm{pF}$ \\
Coupling capacitance $C_{k}$ & $0.54 \mathrm{pF}$ \\
\hline
\end{tabular}

We notice that all the calculated values of different parameters are according with technical integration.

\section{S-Parameters Concept}

From the electrical model (Fig. 10), we can easily calculate the scattering parameters of the octagonal planar transformer [16]:

First, we calculate the ABCD matrices for each block.

$$
\begin{aligned}
& {\left[\begin{array}{ll}
\mathrm{A} & \mathrm{B} \\
\mathrm{C} & \mathrm{D}
\end{array}\right]_{\alpha}=\left[\begin{array}{cc}
1 & 0 \\
\frac{1}{j \omega C_{o x}}+R_{m a g}+\frac{R_{\text {sub }}}{1+j \omega R_{\text {sub }} C_{\text {sub }}} & 1
\end{array}\right]} \\
& {\left[\begin{array}{ll}
\mathrm{A} & \mathrm{B} \\
\mathrm{C} & \mathrm{D}
\end{array}\right]_{\beta}=\left[\begin{array}{cc}
1 & R_{S} \\
0 & 1
\end{array}\right]} \\
& {\left[\begin{array}{ll}
\mathrm{A} & \mathrm{B} \\
\mathrm{C} & \mathrm{D}
\end{array}\right]_{\gamma}=-\left[\begin{array}{cc}
\frac{L}{M} & j \omega\left(\frac{L^{2}}{M}-M\right) \\
\frac{1}{j \omega M} & \frac{L}{M}
\end{array}\right]} \\
& {\left[\begin{array}{ll}
\mathrm{A} & \mathrm{B} \\
\mathrm{C} & \mathrm{D}
\end{array}\right]_{\delta}=\left[\begin{array}{cc}
1 & R_{S} \\
0 & 1
\end{array}\right]} \\
& {\left[\begin{array}{cc}
\mathrm{A} & \mathrm{B} \\
\mathrm{C} & \mathrm{D}
\end{array}\right]_{\varepsilon}=\left[\begin{array}{cc}
1 & 0 \\
\frac{1}{j \omega C_{\text {ox }}}+R_{\text {mag }}+\frac{R_{\text {sub }}}{1+j \omega R_{\text {sub }} C_{\text {sub }}} & 1
\end{array}\right]} \\
& {\left[\begin{array}{ll}
\mathrm{A} & \mathrm{B} \\
\mathrm{C} & \mathrm{D}
\end{array}\right]_{\varphi}=\left[\begin{array}{cc}
1 & \frac{1}{j \omega C_{k}} \\
0 & 1
\end{array}\right]}
\end{aligned}
$$

From where

$$
M=k \cdot L
$$

Second, we can associate the blocks $\alpha, \beta, \gamma, \delta, \varepsilon, \varphi$ in cascade:

$\left[\begin{array}{ll}\mathrm{A} & \mathrm{B} \\ \mathrm{C} & \mathrm{D}\end{array}\right]_{I}=\left[\begin{array}{ll}\mathrm{A} & \mathrm{B} \\ \mathrm{C} & \mathrm{D}\end{array}\right]_{\alpha} \cdot\left[\begin{array}{ll}\mathrm{A} & \mathrm{B} \\ \mathrm{C} & \mathrm{D}\end{array}\right]_{\beta} \cdot\left[\begin{array}{ll}\mathrm{A} & \mathrm{B} \\ \mathrm{C} & \mathrm{D}\end{array}\right]_{\gamma} \cdot\left[\begin{array}{ll}\mathrm{A} & \mathrm{B} \\ \mathrm{C} & \mathrm{D}\end{array}\right]_{\delta} \cdot\left[\begin{array}{ll}\mathrm{A} & \mathrm{B} \\ \mathrm{C} & \mathrm{D}\end{array}\right]_{\varepsilon} \cdot\left[\begin{array}{ll}\mathrm{A} & \mathrm{B} \\ \mathrm{C} & \mathrm{D}\end{array}\right]_{\varphi}$

Third, we can associate the large intermediate block I with block $\varphi$ in parallel to obtain he final ABCD matrix of the entire transformer $F$ :

$\left[\begin{array}{ll}\mathrm{A} & \mathrm{B} \\ \mathrm{C} & \mathrm{D}\end{array}\right]_{F}=\frac{1}{B_{I}+B_{\varphi}} \cdot\left[\begin{array}{cc}A_{I} B_{\varphi}+A_{\varphi} B_{I} & B_{I} \cdot B_{\varphi} \\ \left(C_{I}+C_{\varphi}\right) \cdot\left(B_{\varphi}+B_{I}\right)+\left(D_{I}-D_{\varphi}\right) \cdot\left(A_{\varphi}-A_{I}\right) & D_{\varphi} B_{I}+D_{I} B_{\varphi}\end{array}\right](33)$

Finally, we convert the A, B, C, D parameters to Sparameters as follows:

$$
\left\{\begin{array}{ll}
S_{11}=\frac{\mathrm{A}_{\mathrm{F}}+\frac{\mathrm{B}_{\mathrm{F}}}{\mathrm{Z}_{0}}-\mathrm{C}_{\mathrm{F}} \cdot \mathrm{Z}_{0}-\mathrm{D}_{\mathrm{F}}}{\mathrm{A}_{\mathrm{F}}+\frac{\mathrm{B}_{\mathrm{F}}}{\mathrm{Z}_{0}}+\mathrm{C}_{\mathrm{F}} \cdot \mathrm{Z}_{0}+\mathrm{D}_{\mathrm{F}}} & S_{12}=\frac{2 \cdot\left(\mathrm{A}_{\mathrm{F}} \cdot \mathrm{D}_{\mathrm{F}}-\left(\mathrm{B}_{\mathrm{F}} \cdot \mathrm{C}_{\mathrm{F}}\right)\right)}{\mathrm{A}_{\mathrm{F}}+\frac{\mathrm{B}_{\mathrm{F}}}{\mathrm{Z}_{0}}+\mathrm{C}_{\mathrm{F}} \cdot \mathrm{Z}_{0}+\mathrm{D}_{\mathrm{F}}} \\
S_{21}=\frac{2}{\mathrm{~A}_{\mathrm{F}}+\frac{\mathrm{B}_{\mathrm{F}}}{\mathrm{Z}_{0}}+\mathrm{C}_{\mathrm{F}} \cdot \mathrm{Z}_{0}+\mathrm{D}_{\mathrm{F}}} & S_{22}=\frac{-\mathrm{A}_{\mathrm{F}}+\frac{\mathrm{B}_{\mathrm{F}}}{\mathrm{Z}_{0}}-\mathrm{C}_{\mathrm{F}} \cdot \mathrm{Z}_{0}+\mathrm{D}_{\mathrm{F}}}{\mathrm{A}_{\mathrm{F}}+\frac{\mathrm{B}_{\mathrm{F}}}{\mathrm{Z}_{0}}+\mathrm{C}_{\mathrm{F}} \cdot \mathrm{Z}_{0}+\mathrm{D}_{\mathrm{F}}}
\end{array}\right\}(34)
$$

$Z_{0}$ is the characteristic impedance of the line. Due to reciprocity, $\mathrm{A}_{\mathrm{F}} \cdot \mathrm{D}_{\mathrm{F}}-\mathrm{B}_{\mathrm{F}} \cdot \mathrm{C}_{\mathrm{F}}=1$; therefore, $S_{12}=S_{21}$.

From the $\mathrm{S}$-parameters, we can obtain the $Z$-parameters such that:

$\left\{\begin{array}{ll}\mathrm{Z}_{11}=\mathrm{Z}_{0} \cdot \frac{\left(1+\mathrm{S}_{11}\right) \cdot\left(1-\mathrm{S}_{22}\right)+\mathrm{S}_{21} \cdot \mathrm{S}_{12}}{\left(1-\mathrm{S}_{11}\right) \cdot\left(1-\mathrm{S}_{22}\right)-\mathrm{S}_{21} \cdot \mathrm{S}_{12}} & \mathrm{Z}_{12}=\mathrm{Z}_{0} \cdot \frac{2 \cdot \mathrm{S}_{12}}{\left(1-\mathrm{S}_{11}\right) \cdot\left(1-\mathrm{S}_{22}\right)-\mathrm{S}_{21} \cdot \mathrm{S}_{12}} \\ \mathrm{Z}_{21}=\mathrm{Z}_{0} \cdot \frac{2 \cdot \mathrm{S}_{21}}{\left(1-\mathrm{S}_{11}\right) \cdot\left(1-\mathrm{S}_{22}\right)-\mathrm{S}_{21} \cdot \mathrm{S}_{12}} & \mathrm{Z}_{22}=\mathrm{Z}_{0} \cdot \frac{\left(1-\mathrm{S}_{11}\right) \cdot\left(1+\mathrm{S}_{22}\right)+\mathrm{S}_{21} \cdot \mathrm{S}_{12}}{\left(1-\mathrm{S}_{11}\right) \cdot\left(1-\mathrm{S}_{22}\right)-\mathrm{S}_{21} \cdot \mathrm{S}_{12}}\end{array}\right\}$

From the $Z$-parameters, we can obtain the primary and secondary inductances $(L p, L s)$ and series resistances (Rsp, Rss) (expressions 36 and 37),

$$
\begin{array}{cc}
\mathrm{L}_{\mathrm{p}}=\frac{\operatorname{Im}\left(\mathrm{Z}_{11}\right)}{\omega} & \mathrm{L}_{\mathrm{s}}=\frac{\operatorname{Im}\left(\mathrm{Z}_{22}\right)}{\omega} \\
\mathrm{R}_{\mathrm{sp}}=\operatorname{Re}\left(\mathrm{Z}_{11}\right) & \mathrm{R}_{\mathrm{ss}}=\operatorname{Re}\left(\mathrm{Z}_{22}\right)
\end{array}
$$

Fig. 11 shows the characteristics of inductance behavior. We observe that there are three distinct zones. The inductive behavior until $100 \mathrm{MHz}$, the capacitive behavior beyond operating frequency and the transition zone in which the value of the inductances becomes negative with a zero crossing corresponding to the resonant frequency of the 
inductance.

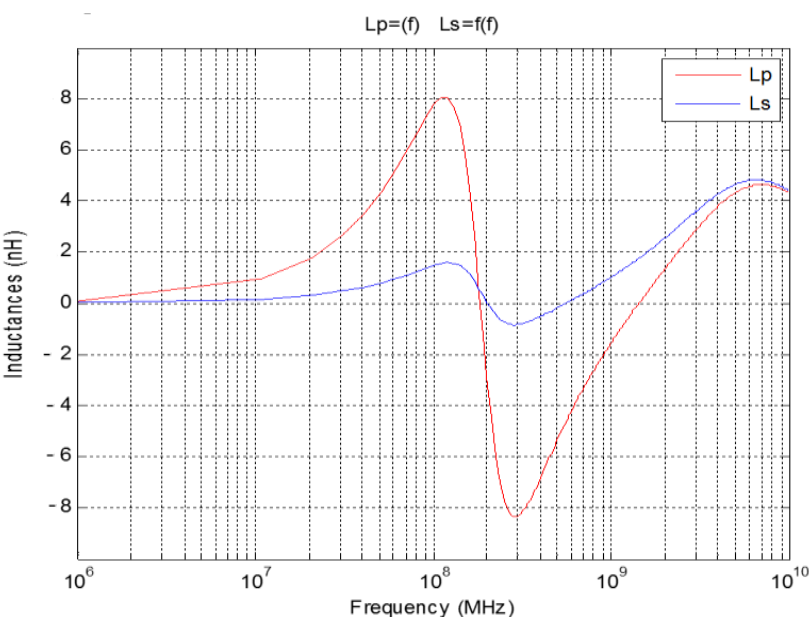

Fig. 11. Primary and secondary inductances versus frequency.

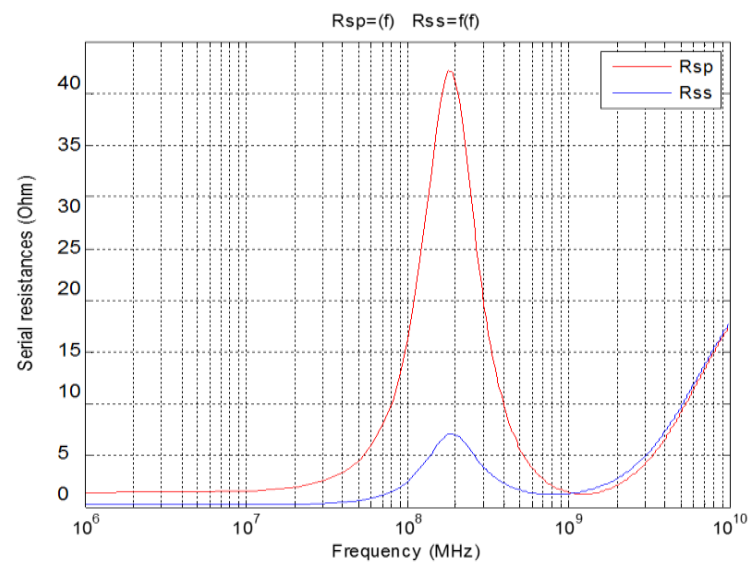

Fig. 12. Primary and secondary serial resistances versus frequency.

Fig. 12 demonstrates the influence of the frequency on series resistances of primary and secondary transformer coils. We notice that the inductances become purely resistive at $100 \mathrm{MHz}$ operating frequency.

The quality factor expresses losses in the transformer coils (Eq. 38),

$$
Q=2 \pi \cdot \frac{\text { stocked energy }}{\text { dissipate denergy }}
$$

It is also proportional to the difference between the maximum magnetic energy and the energy supply [17] (Eq. 39),

$$
Q=\frac{\omega \cdot L}{R_{S}} \cdot \frac{R_{p}}{R_{p}+\left[\left(\frac{\omega L}{R_{S}}\right)^{2}+1\right] R_{S}} \cdot\left[1-\frac{R_{S}^{2}\left(C_{s}+C_{p}\right)}{L}-\omega^{2} L\left(C_{s}+C_{p}\right)\right](39)
$$

In expression 39, the first term corresponds to the simplified quality factor, the second term expresses the losses substrate and the third represents the self-resonance factor, $L$ is the inductance, $R s$ is the serial resistance, $C s$ is the serial capacitance, $\omega$ is the pulsation. $R p$ and $C p$ are the coupling resistance and capacitance; they are related to the substrate resistance and capacitance $R_{S i}$ and $C_{s i}$ and the oxide capacitance $C_{o x}$ (Eq. 40 and Eq. 41 ):

$$
\begin{aligned}
& R_{p}=\frac{1}{\omega^{2} C_{o x}^{2} R_{s i}}+\frac{R_{s i}\left(C_{o x}+C_{p}\right)^{2}}{C_{o x}^{2}} \\
& C_{p}=C_{o x} \frac{1+\omega^{2}\left(C_{o x}+C_{s i}\right) C_{s i} R_{s i}^{2}}{1+\omega^{2}\left(C_{o x}+C_{s i}\right)^{2} R_{s i}^{2}}
\end{aligned}
$$

From the Z-parameters, we can obtain the primary and secondary quality factors $(Q p, Q s)$ (Eq. 42$)$,

$$
Q_{p}=\frac{\operatorname{Im}\left(Z_{11}\right)}{\operatorname{Re}\left(Z_{11}\right)} \quad Q_{s}=\frac{\operatorname{Im}\left(Z_{22}\right)}{\operatorname{Re}\left(Z_{22}\right)}
$$

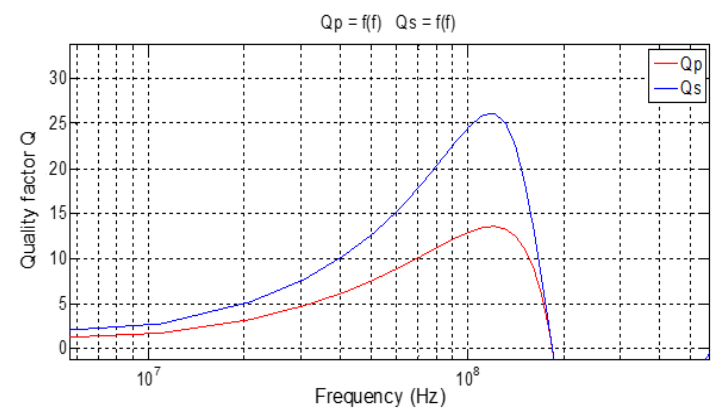

Fig. 13. Quality factor of the primary and secondary coils versus frequency.

Fig. 13 shows the evolution of the quality factor as a function of frequency for the primary and secondary coils. We notice that the first part of the curve corresponds to the zone where the coils have an inductive behavior. Then, the quality factor increases with the frequency until reaching a maximum value, which corresponds to the losses. Beyond the operating frequency, the quality factor decreases to zero at an operating point corresponding to the resonant frequency.

\section{ELECTROMAGNETIC BEHAVIOR OF TRANSFORMER}

Using COMSOL Multiphysics 4.3 software,which is based on finite elements method, we present 3D simulation of electromagnetic effects on the transformers at high frequency $(100 \mathrm{MHz})$.

\section{A. Mathematical Model}

The electromagnetic phenomenon is obtained by solving the Maxwell equations [12]. These last allow us to visualize the distribution of the electric potential on the planar transformer coils and the density of electric current and as well as the magnetic field lines. The expressions are as follows;

$$
\begin{gathered}
\nabla \times \vec{H}=\vec{J} \\
\nabla \times \vec{A}=\vec{B} \\
\vec{E}=-\nabla V-j \omega \vec{A} \\
\vec{J}=\sigma \vec{E}+j \omega \vec{D} \\
\nabla \cdot \vec{J}=0 \\
\vec{B}=\mu_{0} \mu_{r} \vec{H} \\
\vec{D}=\varepsilon_{0} \varepsilon_{r} \vec{E}
\end{gathered}
$$

$\vec{H}$ : Magnetic field [A/m]

$\vec{B}$ : Magnetic flux density [T]

$\vec{J}$ : Electric current density $\left[\mathrm{A} / \mathrm{m}^{2}\right]$

$\vec{E}$ : Electric field $[\mathrm{V} / \mathrm{m}]$

$\vec{A}$ : Magnetic vector potential [Wb/m]

$\vec{D}$ : Electric displacement field standard $\left[\mathrm{c} / \mathrm{m}^{2}\right]$

The boundary conditions on the study area boundaries are demonstrate by the following Equations; 


$$
\begin{gathered}
\vec{n} \cdot \vec{A}=0 \\
n_{x} \cdot A_{x}+n_{y} \cdot A_{y}+n_{z} \cdot A_{z}=0 \\
\vec{n} \cdot \vec{J}=0
\end{gathered}
$$

The normal vector at the boundary (Eq. 51),

$$
\vec{n}=n_{x} \cdot \vec{\imath}+n_{y} \cdot \vec{\jmath}+n_{z} \cdot \vec{k}
$$

Hence,

$$
n_{x} \cdot J_{x}+n_{y} \cdot J_{y}+n_{z} \cdot J_{z}=0
$$

To have a good precision, we proceed to an extremely fine mesh. Fig. 14 illustrates the 3D fine mesh of the octagonal integrated transformer for only the two coils and for the global structure with the different layers.

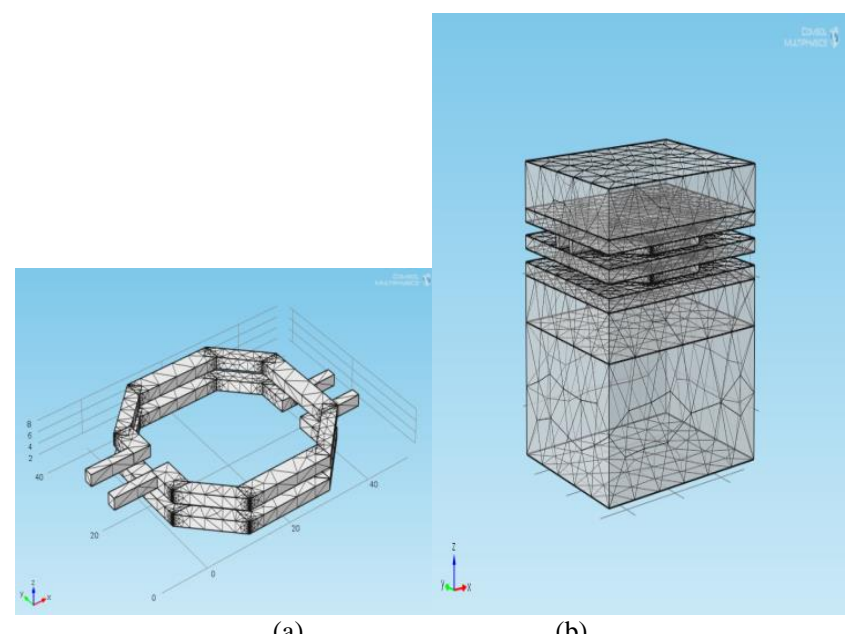

Fig. 14. 3D mesh transformer: (a) Octagonal coils geometry, (b) Global structure with different layers.

Fig. 15 illustrates the electric current density on the planar octagonal coils at $100 \mathrm{MHz}$; on which, we notice that the current is mostly concentrated on the edges of the conductors for high frequency; this effect is due to the skin effect in the rectangular area of conductor.

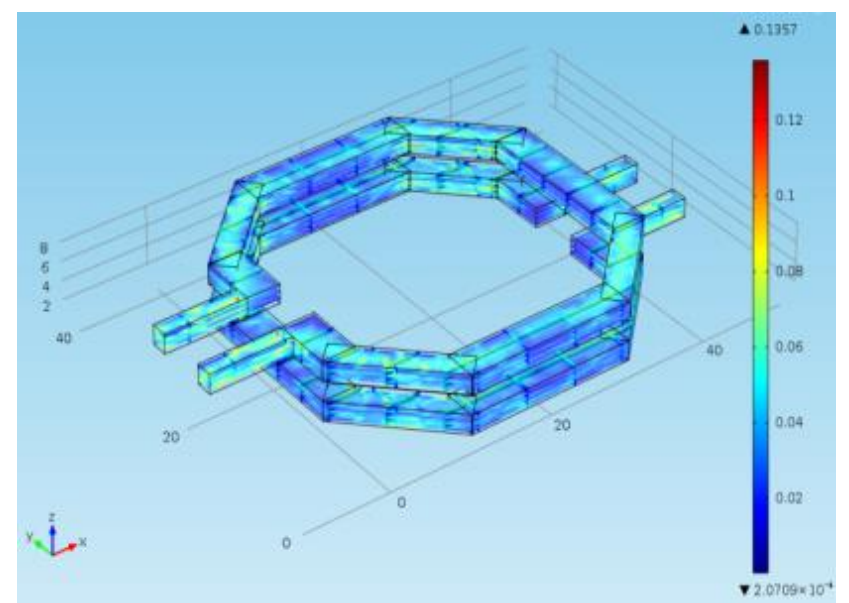

Fig. 15. Current density distribution in the octagonal planar coils at 100 $\mathrm{MHz}$.

Fig. 16 illustrates the electric potential distribution on planar coils of the octagonal transformer. The color of the flow current represents the magnitude of the electric potential. We notice that this last is maximum at the entry of current and decreases along the coil due to the conductor's resistance.

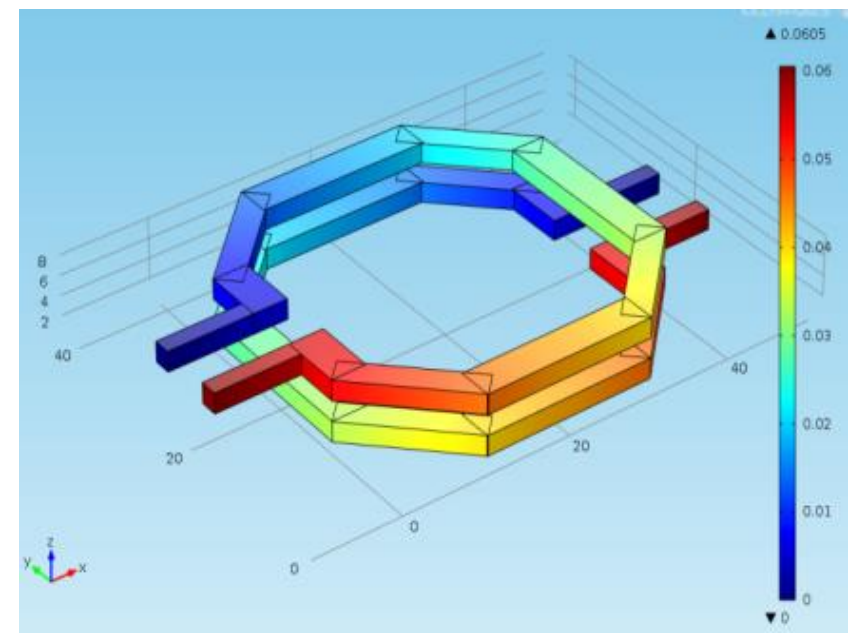

Fig. 16. Electrical potential distribution in planar octagonal coils.

Fig. 17 illustrates the distribution of magnetic field lines in the octagonal planar transformer composed of copper coils deposited on ferrite NiZn magnetic layer and isolated by a dielectric layer, all these layers are deposited on a silicon substrate. We notice that the magnetic field lines are concentrated in the transformer and that is due to the ferrite layer.

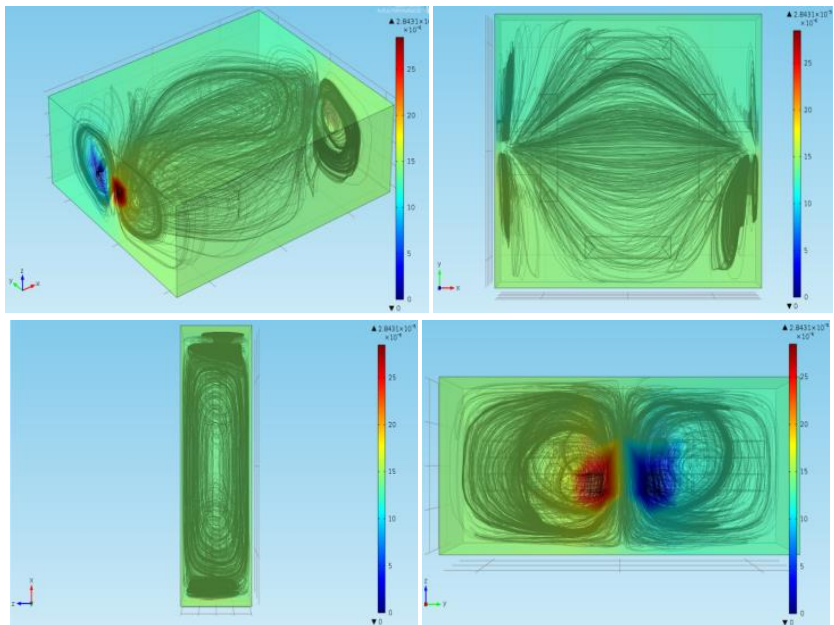

Fig. 17. Distribution of magnetic field lines in the transformer.

\section{CONCLUSION}

The aim of this work is the geometrical dimensioning of the transformer and its electromagnetic modeling to integrate it into a converter. This transformer is destined for the mobile and embedded electronic field requiring an energy conversion of low power and a very high frequency range. The integrated transformer is composed also of a stack of several layers of different materials, which are two copper coils, magnetic layers of ferrite material, insulating layers of dielectric material and a substrate of semiconductor material. The geometry of the planar coils constituting the transformer is octagonal with 45 degrees of angles to avoid the concentrated current in the corners. To determine the geometrical parameters, we have opted for the Wheeler method, which presents a low error compared with other methods. After, we have used the geometrical parameters to extract the electrical parameters, which present the parasitic effects in the different layers of transformer at the high frequency. In addition, we have used 
a finite elements simulator to visualize the distribution of magnetic field lines, electrical potential and current density in the planar octagonal transformer. Besides, we have used another software simulator to validate our results; thus, we have compared the output voltage and current of the flyback in three cases of transformer. The waveforms of the converter's currents and voltages containing the integrated transformer were in accordance with those of the literature and the measured values were very close to its ideal case.

\section{CONFLICT OF INTEREST}

The author declares that the paper is carried out without a conflict of interest.

\section{AUTHOR CONTRIBUTIONS}

The author has done all the work by himself.

\section{REFERENCES}

[1] C. Wang, H. Liao, Y. Xiong, C. Li, R. Huang, and Y. Wang, "A physics-based equivalent-circuit model for on-chip symmetric transformers with accurate substrate modeling," IEEE Transactions on Microwave Theory and Techniques, vol. 57, no. 4, pp. 980-990, 2009.

[2] D. Belot, B. Leite, E. Kerherve, and J. B. Begueret, "Millimeter-wave transformer with a high transformation factor and a low insertion loss," U.S. Patent Application 12/787,782, 2010.

[3] M. Derkaoui, R. Melati, and A. Hamid, "Modeling of a planar inductor for converters low power," in Proc. Global Conference on renewables and Energy Efficiency for Desert Regions GCREEDER'11, 2011, Jordanie.

[4] R. Melati, A. Hamid, T. Lebey, and M. Derkaoui, "Design of a new electrical model of a ferromagnetic planar inductor for its integration in a micro-converter," Mathematical and Computer Modelling, vol. 57, pp. 200-227, Janvier 2013.

[5] Y. Benhadda, A. Hamid, T. Lebey, and M. Derkaoui, "Design and modeling of an integrated inductor in a Buck converter DC-DC," Journal of Nano- and Electronic Physics, vol. 7, no. 2, 10 June 2015.

[6] A. S. Ezzulddin, M. H. Ali, and M. S. Abdulwahab, "On-chip RF transformer performance improvement technique," Eng. \& Tech. Journal, vol. 28, no. 4, 2010.

[7] Z. Ouyang, O. C. Thomsen, and M. A. E. Andersen, "Optimal design and tradeoff analysis of planar transformer in high-power DC-DC converters," IEEE Transactions on Industrial Electronics, January 25, 2010.

[8] C. P. Yue and S. S. Wong, "Physical modeling of spiral inductors on silicon," IEEE Transactions on Electron Devices, vol. 47, no. 3, 2000.

[9] M. Yamaguchi, T. Kuribara, and K.-I. Arai, "Two port type ferromagnetic RF integrated inductor," in Proc. IEEE International Microwave Symposium, IMS-2002, TU3C-2, Seattle, USA, 2002, pp. 197-200.

[10] A. Telli, S. Demir, and M. Askar, "Practical performance of planar spiral inductors," IEEE, 2004, pp. 487-490.

[11] B. Estibals and A. Salles, "Design and realization of integrated inductor with low DC-resistance value for integrated power applications," HAIT Journal of Science and Engineering B, vol. 2, issues 5-6, pp. 848-868, 2005.

[12] M. Derkaoui, A. Hamid, T. Lebey, and R. Melati, "Design and modeling of an integrated transformer in aflyback converter," Telecommunication, Computing, Electronics and Control, vol. 11, no. 4, pp. 669-682, December 2013.

[13] B. Estibals, J. L. Sanchez, C. Alonso, H. Camon, and J. P. Laur, "Vers l'intégration de convertisseurs pour l'alimentation des microsystèmes," J3EA, Journal sur l'Enseignement des Sciences et Technologies de l'Information et des Systèmes, vol. 2, 2003.

[14] Y. K. Koutsoyannopoulos, "Systematic analysis and modeling of integrated inductors and transformers in RF IC design," Analog and Digital Signal Processing, vol. 47, no. 8, p. 699, August 2000.

[15] C. Alonso, "Contribution à l'optimisation, la gestion et le traitement de l'énergie," Université PaulSabatier - Toulouse III, 2003.

[16] A. Abdeldjebbar, A. Hamid, Y. Guettaf, and R. Melati, Design of Micro-Transformer in Monolithic Technology for High Frequencies Fly-Back Type Converters, 2018.

[17] J. Aguilera and Berenguer, Design and Test of Integrated Inductors for RF Applications, Kluwer Academic Publishers, 2004.

Copyright $($ ) 2020 by the authors. This is an open access article distributed under the Creative Commons Attribution License which permits unrestricted use, distribution, and reproduction in any medium, provided the original work is properly cited (CC BY 4.0).

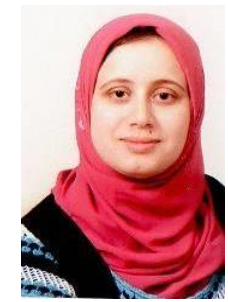

Mokhtaria Derkaoui is an associate professor, a $\mathrm{PhD}$ in electrical engineering and a young researcher in microelectronics from the University of Sciences and Technologies of Oran USTO, Algeria. She actually teaches modules in digital electronics and optoelectronics at the National Institute of Telecommunication \& ICT of Oran INTTIC, Algeria. She is a member of research team of LEPA and LARATIC laboratories since 2010 and 2015 respectively. 